$1-1-2003$

\title{
A Comparison of the Perceived Importance of Information Systems Development Strategies by Developers from the United States and Korea
}

Chung S. Kim

Missouri State University

Dane K. Peterson

Missouri State University

Follow this and additional works at: https://bearworks.missouristate.edu/articles-cob

\section{Recommended Citation}

Kim, Chung S., and Dane K. Peterson. "A comparison of the perceived importance of information systems development strategies by developers from the United States and Korea." In Advanced Topics in Information Resources Management, Volume 3, pp. 197-217. IGI Global, 2004.

This article or document was made available through BearWorks, the institutional repository of Missouri State University. The work contained in it may be protected by copyright and require permission of the copyright holder for reuse or redistribution.

For more information, please contact BearWorks@library.missouristate.edu. 


\title{
A Comparison of the Perceived Importance of Information Systems Development Strategies by Developers from the United States and Korea
}

Chung S. Kim and Dane K. Peterson, Southwest Missouri State University, USA

\begin{abstract}
This study examined the perceptions of Information Systems (IS) developers from the U.S. and Korea with regards to the strategies that are considered crucial for IS success. The results of a principal component analysis revealed that the IS development strategies could be classified into four categories: (1) Organizational Integration, (2) Team Member Characteristics, (3) Project Leader Traits, and (4) Project Development Management. ANOVA results indicated that developers from both countries viewed Organizational Integration as the most important component and Project Development Management as the least important component. However, while IS developers in the U.S. viewed Team Member Characteristics as the second most important component, Korean IS developers rated the Project Leader Traits as the second most important component. Moreover, the IS developers from the U.S. rated Organizational Integration and Team Member Characteristics as significantly more important than did the IS developers from Korea. The results were discussed in terms of Hofstede's model of national culture.
\end{abstract}

Keywords: IS developers; IS integration; project development management

\section{INTRODUCTION}

In spite of significant technological advances and years of application experience, the development of information systems remains a difficult process plagued with uncertainty (Liebowitz, 1999). While many systems development projects have been successful, many others have failed (Clegg et al., 1998). Numerous studies have been conducted to investigate various development strategies that are associated with IS success (e.g., Abdul-Gader, 1997; Baker, Murphy \& Fisher, 1983; 
Cleland \& King, 1983). Most of these studies have been confined to data collected in the U.S. and other countries with a similar culture. However, the results of investigations conducted in the U.S. regarding the usefulness of various IS development strategies may not be relevant in a global environment.

It has been suggested that as corporations develop and implement global IS, it may be necessary to modify their operating procedures to accommodate the customs of IS developers in the host country (Katz \& Townsend, 2000). Thus, a pertinent issue is, how do the IS development strategies believed to be most important in the U.S. compare with the strategies considered to be most important in other nations and other cultures? An understanding of national and cultural differences and similarities with respect to the perceived importance of IS development strategies could prove to be extremely valuable to managers of global IS.

Not only has most of the research on IS development strategies been conducted in nations characterized by a Western culture, but most of the investigations have assessed the value of IS development strategies based on the views of users. That is, measures such as user satisfaction, system usage, and the perceived benefits of the system as assessed by users are typically employed to determine the effectiveness of various IS development strategies (Ginzberg, 1981; McDoniel, Palko, \& Cronan, 1993). To some extent, the views of IS developers have been neglected in research on IS development strategies (Lyytinen, 1998).

However, IS developers make a series of important decisions associated with project management and resource allocation during the complex and unstructured process of system development (Dos Santos \& Hawk, 1988). IS developers are often responsible for defining, interpreting, and implementing various IS development strategies (Kumar \& Bjorn-Anderson, 1990). They have to assess users' needs and monitor the progress of projects to ensure successful completion (Jiang, Klein, \& Balloun, 1998). Thus, how developers view IS strategies will influence their decision making and consequently the likelihood of IS success. If IS developers fail to realize the value of certain crucial strategies, an IS project could fail to accomplish its goals. For example, it has been suggested that the failure of some IS projects may be due to the possibility that developers are overly concerned with the technical aspects of IS development and fail to realize the importance of strategies that are necessary to ensure proper alignment of IS with business goals (Dos Santos \& Hawk, 1988; Jiang et al., 1998). Thus, an understanding of how IS developers view various strategies may be useful to managers in coordinating the development of IS projects (Kumar \& Bjorn-Andersen, 1990).

The present study compared the perceptions of IS developers in the U.S. with IS developers from South Korea (henceforth, referred to only as Korea) in terms of the perceived importance of potential strategies associated with IS success. There are a couple of reasons why a comparison between U.S and Korea is important. First, there is a close alliance between the two countries (Chung, Lee, \& Jung, 1997). For instance, there are currently a number of economical ties between the two nations, with both countries having subsidiaries and actively marketing goods and services in the other country. In addition, there are a large number of joint ventures and mergers taking place between the U.S. 
and Korea. Several educational exchange programs also exist between the two countries. As a result, many scholars in Korea have been educated in the U.S. during the last few decades. Due to the numerous ties between the two countries, it might be reasonable to expect that the developers from the two nations would have similar views regarding the importance of various IS development strategies.

A second reason why a comparison between the U.S. and Korea might be of interest is the vast cultural differences between the two countries (Hofstede, 1980). Cultural differences are often cited as a reason that IS development in a global environment may differ from the strategies that have been found to be successful in the U.S. (Shore, 1998; Shore \& Venkatachalam, 1994). Cultural differences have particularly proven to be a major obstacle in global IS development when Asian offices are involved (Burnson, 1989). Thus, it is possible that cultural differences could contribute to differences in the perceived importance of IS development strategies.

\section{NATIONAL CULTURE}

National culture distinguishes the members of one group or category of people from another (Hofstede, 1980). Since each culture has unique values to guide human behavior, national culture strongly affects management practices including policy making (Earley, 1993; Garfield \& Watson, 1997). It has also been demonstrated that the management of global Information Technology (IT) is influenced by national culture (Abdul-Gader, 1997).

Hofstede's (1980) research on cultural dimensions has provided a theoretical framework that has been used to account for empirical observations in numerous IS studies, including studies on cultural differences in the adoption and use of IT (e.g., Garfield \& Watson, 1997; Earley, 1993; Katz \& Townsend; 2000). Hofstede investigated national culture by surveying over 12,000 employees of the IBM Corporation working in various subsidiaries located in 50 different countries. His research examined fundamental differences in the way in which groups perceived the organizational work climate, and the employees' values regarding general ideological factors such as competition in the workplace, earnings, and job security (Sekaran $\&$ Snodgrass, 1986). Based on the survey results, Hofstede proposed a model of national culture consisting of four dimensions: (1) individualism-collectivism, denoting the extent to which individuals view the importance of achieving personal goals versus the achievement of group goals; (2) power distance, or the extent to which the less powerful members in society accept that power is unequally distributed; (3) masculinity-femininity which relates to the dominant values in a culture, such as the importance of money and personal recognition as opposed to the importance of society and the quality of life; and (4) uncertainty avoidance, or the extent to which individuals prefer to avoid uncertainty.

The validity of these dimensions has been established in a number of studies (Garfield \& Watson, 1997; Ronen \& Shankar, 1985; Sekaran \& Snodgrass; 1986). In addition, Hofstede's framework has been used in a multitude of studies across many disciplines and has been proven to be stable (see Sondergaard, 1990 for a review of the literature). 


\section{CULTURAL CHARACTERISTICS OF THE U.S. AND KOREA}

Table 1 summarizes Hofstede's analysis of the two countries examined in this investigation based on the four national culture dimensions. The cultural differences illustrated in Table 1 suggest possible differences in the manner in which the developers from the two countries may view IT. According to Hofstede's dimensions of national culture, the U.S. culture is characterized as low in uncertainty avoidance and high in masculinity. Members of a culture that are low in uncertainty avoidance and high in masculinity tend to be more aggressive and willing to take risks. The aggressive, competitive, and risk-seeking

Table 1 .

\begin{tabular}{|c|c|c|}
\hline & USA & South Korea \\
\hline Power Distance & Relatively Low (40) & Relatively High (60) \\
\hline & $\begin{array}{l}\text { - Subordinates expect to be } \\
\text { consulted } \\
\text { - The ideal boss is resourceful } \\
\text { democrat } \\
\text { - Hierarchy in organizations is } \\
\text { established for roles and } \\
\text { convenience } \\
\text { - Inequality among people } \\
\text { should be minimized }\end{array}$ & $\begin{array}{l}\text { - Subordinates expect to be } \\
\text { obedient } \\
\text { - The ideal boss is a benevolent } \\
\text { autocrat } \\
\text { - Hierarchy in organizations } \\
\text { reflects the existential inequality } \\
\text { - Inequalities among people are } \\
\text { both expected and desired. }\end{array}$ \\
\hline \multirow{2}{*}{$\begin{array}{l}\text { Individual- } \\
\text { collectivism }\end{array}$} & High Individualism (91) & Low Individualism (18) \\
\hline & $\begin{array}{l}\text { Individuals have autonomy } \\
\text { and freedom to pursue their goals. } \\
\text { Identify is based in the } \\
\text { individual } \\
\text { - Relationship of employer- } \\
\text { employee is a contract } \\
\text { Hiring and promotion are } \\
\text { based on skills } \\
\text { Task prevails over the } \\
\text { relationship }\end{array}$ & $\begin{array}{l}\text { - Individuals look after one } \\
\text { another } \\
\text { - Identify is based in the social } \\
\text { network } \\
\text { - Relationship is based on } \\
\text { family links } \\
\text { - Hiring and promotion are } \\
\text { partially based on employee's in- } \\
\text { group } \\
\text { - Relationship prevails over the } \\
\text { task }\end{array}$ \\
\hline \multirow[t]{2}{*}{$\begin{array}{l}\text { Uncertainty } \\
\text { Avoidance }\end{array}$} & Relatively Low Avoidance (46) & High Avoidance (85) \\
\hline & $\begin{array}{l}\text { - Accept the uncertainty of } \\
\text { future } \\
\text { - Do not want strict guidelines } \\
\text { - Teamwork span departmental } \\
\text { boundaries } \\
\text { - Managers/leaders are } \\
\text { arbitrator }\end{array}$ & $\begin{array}{l}\text { - Stressed by the threat of } \\
\text { uncertainty } \\
\text { - Need for rules and legal } \\
\text { measures to reduce the stress } \\
\text { - Managers/leaders have } \\
\text { expertise and knowledge }\end{array}$ \\
\hline \multirow[t]{2}{*}{$\begin{array}{l}\text { Masculinity- } \\
\text { Femininity }\end{array}$} & Relatively High Masculinity (62) & $\begin{array}{c}\text { Relatively Low Masculinity } \\
\text { (39) }\end{array}$ \\
\hline & $\begin{array}{l}\text { - Stress on equity, competition } \\
\text { among colleagues } \\
\text { - Live in order to work } \\
\text { - Resolution of conflicts by } \\
\text { fighting it out. } \\
\text { - Value money and achievement }\end{array}$ & $\begin{array}{l}\text { - Stress on relationship among } \\
\text { people } \\
\text { - Work in order to live } \\
\text { - Resolution based on } \\
\text { compromise } \\
\text { - Value quality of life and the } \\
\text { preservation of the environment }\end{array}$ \\
\hline
\end{tabular}

Copyright (C) 2003, Idea Group Inc. Copying or distributing in print or electronic forms without written permission of Idea Group Inc. is prohibited. 
nature of the U.S. culture may be well suited for the willingness to use IT in innovative ways and to view IS as a competitive tool (Grover, Segars, \& Durand, 1994; McIntosh, 1999; Park, Chun, Lim, \& Min, 1998). Thus, even though strategic and competitive uses of IS are associated with a high level of risk (Vitale, 1986), the risk-seeking nature of the U.S. insinuates that IS developers from the U.S. may be more inclined to view IT as a strategic resource. Therefore, they may consider development strategies associated with the strategic uses of IS as highly important.

The culture of Korea is characterized as higher in uncertainty avoidance and lower in masculinity than the U.S. culture. Thus, the Korean culture is characterized as less competitive, less aggressive in the pursuit of personal goals, and more riskaverse. These characteristics may be more amendable to a conservative approach to the use of IT. Therefore, national culture may partially explain the tendency in Korea to view IS in more traditional terms (Grover et al., 1994; McIntosh, 1999; Park et al., 1998). Hence, it might be expected that IS developers from Korea would view development strategies' association with strategic uses of IS as less important.

Also of interest in Table 1 is the fact that the U.S. is characterized as low on the power distance dimension. The low power distance nature of the U.S. culture indicates that members are reluctant to accept unequally distributed power. In the U.S., participation and democracy are highly valued and employees expect to have a voice in the decisions made by their organizations. Conversely, Korea is assumed to have a high power distance culture. In a high power distance culture, a hierarchical system with centralized power is generally the norm. Inequality in power is accepted as appropriate and legitimate.
In most cases, there is little perceived need for subordinate participation in the organizational decision-making process. These cultural differences could suggest differences in the perceived importance of IS development strategies. That is, developers from the U.S. might be more apt to view the contributions of the project team members as more important than would the IS developers from Korea. On the other hand, the Korean IS developers may be more likely to view the contributions of project leaders and supervisors as more important than do their counterparts in the U.S.

\section{CRITICAL STRATEGIES FOR SUCCESSFUL IS IMPLEMENTATION}

Numerous studies have investigated strategies that may account for differences between successful and unsuccessful IS projects (e.g., Ewusi-Mensah, 1997; Ginzberg, 1981; Liebowitz, 1999; McDoniel et al., 1993; Pinto \& Prescott, 1990). Based on these studies, 17 strategies were identified that may be considered critical for IS success. Since the respondents in this study were IS developers, the goal was to select strategies that were of particular relevance to IS developers rather than base the selection on the perspectives of the users and management.

It is possible to categorize the 17 strategies according to a number of factors. For example, some of the strategies are related to IS development, while others pertain to the IS environment (Lyytinen, 1988). The literature reviewed in the following sections and a logical analysis of the 17 strategies suggests that one possible classification scheme is to group the strategies into one of following four categories: 
(1) Organizational Integration, (2) Team Member Characteristics, (3) Project Leader Traits, and (4) Project Development Management. Table 2 presents the list of 17 strategies identified for the present study grouped according to the four possible categories.

Table 2: Seventeen IS Development Strategies Organized by Hypothesized Categories

\section{Organizational Integration}

1. Top management support

2. User participation in the project

3. Clearly stated objectives

4. Alignment of project and corporate goals

5. Proper project scope

\section{Team Member Characteristics}

6. Team member experience

7. Team member commitment

8. Team member self-control on the progress

9. Adequate training for the team

\section{Project Leader Traits}

10. Project leader experience

11. Project leader's project monitoring/ control

12. Project leader's feedback to team

\section{Project Development}

\section{Management}

13. Detailed project plan

14. Utilizing an effective methodology

15. Peer review on project progress

16. Utilizing a prototype

17. Use of appropriate technology

\section{Organizational Integration}

Prior research suggests that many IS fail due to a lack of consideration given to organizational issues and the mismatch in the user-system "fit". In order to achieve an appropriate fit between the IS and the individuals using it, the commitment of the stakeholders is critical (Lyytinen, 1988). Two of the most important stakeholder groups are top management and users.

Previous studies indicate that top management support is necessary for success on many types of IS (e.g., Ginzberg, 1981; Jiang, Klein, \& Balloun, 1996; Liebowitz, 1999; McDoniel et al., 1993; Pinto \& Prescott, 1990). Without management support, it is difficult to secure the required resources for IS projects. Top management support is also important to mitigate users' negative attitudes toward a new system and the organizational change that typically follows. The failure of top management to support and also to enforce regularly scheduled management review meetings are known to be a major cause of many IS project failures (EwusiMensah, 1997).

Numerous studies on IS implementation have reported that user participation is critical for IS success (e.g., Ginzberg, 1981; Jiang et al., 1996; Liebowitz, 1999; McDoniel et al., 1993; Pinto \& Prescott, 1990). It is generally recommended that the members of the project team solicit input from all potential users in order to obtain a better understanding of the users' needs and requirements. User participation can result in an improvement in the users' understanding of the system. Active user participation enhances system acceptance by users, builds the commitment needed to create organizational 
changes, ensures a more accurate design specification, and enhances the quality of the system being developed (Roberts, Leigh, \& Purvis, 2000).

User groups and top management should help establish clear goals and objectives for the project to meet the users' needs and to support organizational strategies (Baker et al., 1983; Pinto \& Slevin, 1987). These goals and objectives guide the information requirement phase of the development process (Pinto \& Prescott, 1990). Failure to satisfy this aspect of the project is likely to lead to fragmented efforts and lack of team focus to steer the rest of the development (Ewusi-Mensah, 1997). Moreover, in order to harness the potential of an IS as a competitive tool, it is paramount to align the management information function with the organization's goals and objectives (Nath, 1989; Watson, 1991). Without proper alignment, IS developers may create an IS incapable of providing the right information for the organization and the users.

Users' needs, management expectations, and project resource requirements should determine the scope of the project. The scope of the project defines the boundary of the project or what aspects of the system will be included in the project. It has been shown that proper project scope is related to IS success (Liebowitz, 1999). Projects that are excessively grand in scope tend to have built-in difficulties, higher risks, and levels of complexity that may frustrate even competent development teams (Ewusi-Mensah, 1997). On the other hand, a project with a small scope may not be able to correct fundamental problems and may cause more severe problems in the future.

\section{Team Member Characteristics}

The more experience and skills a project team possesses, the more likely they are to develop a successful IS (EwusiMensah, 1997; Jiang et al., 1996; Liebowitz, 1999). Lack of team members' experience and relevant domain-knowledge has been reported as a major contributor to many project cancellations. Building a successful IS requires team members' commitment (Baker et al., 1983; EwusiMensah, 1997), contributions, and cooperation. The management of projects requires a balance between controls designed by the project leader and autonomous self-control (Kirsch, 1997; Kirsch, \& Cummings, 1996). Self-control is defined as the extent to which an individual exercises freedom of autonomy to determine both what actions are required and how to execute these activities. Self-controlled individuals define their own goals and procedures for accomplishing tasks. Research supports the concept that the performance of technically oriented development teams can improve when the members exhibit self-control (Henderson \& Lee, 1992).

One of the most serious IT problems facing companies in both developed and developing countries is a lack of IT personnel, or more specifically a lack of IT expertise (Bingi et al., 2000). Rapid advances in technology create a need to train team members on a continual basis (Cleland \& King, 1983; Pinto \& Prescott, 1990; Pinto \& Slevin, 1987). The technical competence of the developers is at the core of a number of cancelled projects (Ewusi-Mensah, 1997).

\section{Project Leader Traits}

A competent project leader is vital to project success (Aladwani, 2000; Baker et 
al., 1983; Jiang, et al., 1996; Liebowitz, 1999; Pinto \& Prescott, 1990). The leader's experience, project control, and feedback are necessary to guide and coordinate the activities of the various subgroups involved as well as manage the system development project through the various lifecycle stages. Making allowances for adequate monitoring and feedback mechanisms gives the project leader the ability to anticipate problems, to oversee corrective measures, and to ensure that no deficiencies are overlooked (Pinto \& Slevin, 1987). Without proper guidance from the project leader, the development of an IS is likely to result in failure (Ewusi-Mensah, 1997).

\section{Project Development Management}

Effective project management requires a detailed project plan (Aladwani, 2000; Baker et al., 1983; Cleland \& King, 1995; Ginzberg, 1981; Jiang, et al., 1996; Pinto \& Prescott, 1990). A project plan refers to the degree to which time schedules, milestones, manpower, and equipment requirements are specified. Further, the project plan should include a satisfactory measure that enables the judgment of actual performance against the plan (Pinto \& Slevin, 1987). Detailed plans help control and coordinate the workflow within the IS project (Aladwani, 2000).

An appropriate methodology (or a set of methodologies) is instrumental in helping to manage and control the development of large, complex systems successfully (Lyytinen, 1988; Ratbe, King, \& Kim, 2000; Roberts et al., 2000). Many different development methodologies exist and are usually classified according to themes or features. Some examples include information engineering, structured systems analysis and design methodology, joint ap- plications design, and rapid application development. In order to select the right methodology, developers need to consider the characteristics of the environment such as organizational culture, expertise of the developers, development time frame, and other resource constraints. The consequence of failing to follow an appropriate methodology will yield quality problems and serious maintenance problems later (EwusiMensah, 1997).

A structured walk-through is a widely used technique to provide a test of a proposed system design and is often implemented as a peer feedback and review process. A peer-based review or feedback has been shown to have a significant impact on team performance (Henderson \& Lee, 1992). Peer reviews also improve team members' perceptions of their own involvement in a project, which is believed to influence team performance (Jones \& Harrison, 1996).

Project risks represent a major concern in the IS development process. Project risks relate to the uncertainty about meeting budget targets, attaining system objectives, and gaining user acceptance. These risks increase with the complexity of the system requirements, project size, and the ambiguity of project goals. The literature indicates that prototyping is an effective method of reducing project risks (Ratbe et al., 2000; Shore \& Venkatachalam, 1994).

The development of an IS often requires the adoption of new technology. Systems are currently being developed in an increasingly complex technological environment. Advances in communications network and development tools provide numerous options and alternatives in acquiring hardware and software. The technology infrastructure available in a company 
and technical expertise of the staff needs to be critically assessed in the process of the adoption of an appropriate technology (Ewusi-Mensah, 1997; Jiang, et al., 1996; Pinto \& Prescott, 1990).

\section{OBJECTIVES OF THE STUDY}

In the present study, IS developers from the U.S. and Korea rated the importance of 17 development strategies for IS success. One objective of the current investigation was to examine which strategies are viewed as most critical in terms of IS success by developers from each country. A comparison was also made between the perceived importance of the development strategies to determine possible similarities and differences in the views of IS developers from the U.S. and Korea. In order to achieve these objectives, the present study used a principal component analysis to determine if the 17 strategies could be reduced to a meaningful classification as outlined in Table 2. Following the principal component analysis, statistical tests were conducted to investigate the following research hypotheses.

H1: There will be differences in the perceived importance of the various strategies (or components) by IS developers from the U.S.

H2: There will be differences in the perceived importance of the various IS strategies (or components) by IS developers from Korea.

H3: There will be differences between the views of developers from the U.S. and Korea with respect to the perceived importance of the various strategies (or components).

\section{RESEARCH METHODOLOGY}

\section{Questionnaire}

The questionnaire was pre-tested by 21 faculty members of a CIS department, of which several provided written and oral feedback on the suitability of the 17 strategies. The questionnaire was then pilottested with IS developers from two local companies in the U.S. The IS developers were tested in small groups. They completed the questionnaire first and then provided oral feedback on the list of strategies identified on the instrument. Based on the feedback of the pilot test, some changes were made to improve the clarity and comprehension of the items. The questionnaire was then translated into the Korean language by a faculty member at a university in Korea and pre-tested by several graduate students and faculty members working at the same institution using the same pretest methods used for the English language version. A professor in the U.S. then conducted a back translation to ensure the proper interpretation of the strategies. The 17 strategies were presented in a random order on the questionnaire.

Respondents evaluated the importance of each of the 17 strategies displayed in Table 2 on a seven-point scale ranging from (1) no contribution to (7) a very high contribution with respect to IS success. The questionnaires were distributed to IS developers working in large organizations. A total of 18 organizations were selected based on previous contacts with the organizations through personnel recruitment with the universities. Although the organizations were not randomly selected, there were no obvious reasons why the organizations would not be representative of the population of organizations in each coun- 
try. Using a systematic sampling procedure, between five and 30 IS developers were selected from each company. The number of developers selected from each organization depended largely on the number of IS employees in the organization. All of the respondents who received the questionnaire supplied data. While the selection of organizations did not represent a random selection process, the use of this procedure avoided problems associated with a non-response bias.

\section{Companies}

In addition to the surveys completed by the IS developers, one supervisor from each company filled out a questionnaire with items pertaining to characteristics of the company. The data for the U.S. sample were obtained from eight organizations, in- cluding three in manufacturing and one each in transportation, technology, wholesale/retail, public utility, and government. For the total number of employees in the companies, three had between 500 and 1,000 employees, three had between 1,000 and 5,000 employees, and the remaining two had over 5,000 employees. The number of IS employees ranged from 50 to over 150 . The IS budget was between 5.1 and 10 million dollars for two companies, between 10.1 and 100 million dollars for three companies, over $\$ 500$ million for two companies, and one company left this item blank.

Data for the Korean sample were obtained from ten organizations. Five were consulting- computer service companies, four were in manufacturing, and one company was in the oil industry. Three companies had less than 500 employees, two had between 500 and 1,000 employees; two

\section{Table 3.}

\section{Profile of Respondents by Nationality}

\begin{tabular}{lccc} 
& United States & Korea & Totals \\
\hline & & & \\
Sample Size & 110 & 127 & 237 \\
$\quad$ & & & \\
Gender & 78 & 115 & $193(81.1 \%)$ \\
$\quad$ Males & 32 & 12 & $45(18.9 \%)$ \\
$\quad$ Females & & & \\
$\quad$ Education & 22 & 21 & $43(18.2 \%)$ \\
$\quad$ No College Degree & 64 & 93 & $157(66.2 \%)$ \\
$\quad$ College Degree & 24 & 13 & $37(15.6 \%)$ \\
$\quad$ Graduate Degree & & & \\
$\quad$ & 36.49 & 32.24 & 34.18 \\
Age $\quad$ Mean & 8.40 & 4.42 & 6.85 \\
$\quad$ Standard Deviation & & & \\
$\quad$ & 11.05 & 6.26 & 8.45 \\
Experience & Mean & 4.28 & 6.32 \\
$\quad$ Standard deviation & 7.31 & & \\
$\quad$ & &
\end{tabular}

Copyright $($ C) 2003, Idea Group Inc. Copying or distributing in print or electronic forms without written permission of Idea Group Inc. is prohibited. 
had between 1,000 and 5,000 employees, and the remaining three companies had over 5,000 employees. The number of IS employees ranged from 20 to over 250 . The IS budget was under $\$ 1$ million for one company, between $\$ 1.1$ and 5 million for six companies, between $\$ 5.1$ and 10 million for one company, and over $\$ 10$ million for two companies.

\section{Respondents}

IS developers were asked to provide some biographical information in addition to the importance ratings for the 17 development strategies. Table 3 summarizes the results of the biographical information. As can be seen in Table 3, for both countries the majority of IS developers were males. Only 18.9 percent of the respondents in the survey were females. A majority of the respondents had a least a college degree $(81.8 \%)$. The IS developers in the U.S. were slightly older (36 years of age versus 32) with a little more experience in the field than the Korean IS developers (11 years versus six years).

\section{RESULTS}

To determine if the strategies could be categorized as outlined in Table 2 , the combined data from all developers were analyzed with a principal component analysis as the extraction technique and varimax as the method of rotation. Without specifying the number of factors in advance, four components with eigenvalues greater than one emerged. The Kaiser measure of sampling adequacy was .861 with 56 percent of the variance accounted for by the four components. The results of the component loadings are presented in Table 4. All but one item loaded highest on the component specified in Table 2. It was antici- pated that Item 13-Detailed project planwould load highest on Project Development Management, but instead loaded highest on Project Leader Traits.

The simple structure appears to be adequate for most of the items, with the possible exceptions of Items 12 and 13. In other words, most of the items had a high loading only on one of the four components. One possibility would be to eliminate Items 12 and 13 from the remainder of the analysis. However, the analysis turned out to be essentially the same with the items included as representing the third component as when the items were omitted from the analysis. Therefore the results presented in this paper are based on those obtained when Items 12 and 13 were included as representing Project Leader Traits.

Factor-based scores were computed for each subject based on the principal component analysis. The mean score for each component was then computed for each country separately and the means are displayed in Table 5. The higher the mean values in Table 5, the higher the perceived importance of the component. To examine the perceived importance of the strategies, a 2 (Countries) X 4 (Components) mixed ANOVA was performed on the data. The analysis indicated that the overall difference between the two nations was not significant $(F=0.39, p=.534)$. As can be seen by the grand means in the last row of Table 5, there were essentially no differences in the overall importance ratings between the two countries. This primarily indicates there were no differences between the countries in terms of the manner in which the developer interpreted the scale for measuring the importance of the strategies. The ANOVA results also indicated a significant difference between the four components $(F=59.77, p<.001)$. As can be seen by the grand means in the last col- 
umn of Table 5, the IS developers viewed Organizational Integration as the most crucial factor and Project Development Management as the least important factor. More importantly, the ANOVA yielded a significant interaction between the two countries and the four components $(\mathrm{F}=$ 7.66, $\mathrm{p}<.001)$.

To explore how the developers in each country viewed the relative importance of the four components, a simple main effects analysis was conducted on the data obtained from each country. The simple main effects analysis conducted on the data obtained from U.S developers indicated a significant difference between the four components $(\mathrm{p}<.05)$. Thus, the IS developers from the U.S. did not view each component as equally important. Pairwise comparisons revealed all components differed significantly from each other. Thus, Project Development Management was viewed as

Table 4.

Principal Component Rotated Factor Loadings

\begin{tabular}{lllll} 
& $\begin{array}{c}\text { Organizational } \\
\text { Integration }\end{array}$ & $\begin{array}{l}\text { Team } \\
\text { Member }\end{array}$ & $\begin{array}{c}\text { Project } \\
\text { Leader }\end{array}$ & $\begin{array}{l}\text { Development } \\
\text { Management }\end{array}$ \\
\hline 1. Top management support & $\mathbf{. 6 7 7}$ & -.029 & -.002 & .081 \\
2. User participation & $\mathbf{. 6 3 8}$ & .130 & -.167 & -.008 \\
3. Clearly stated objectives & $\mathbf{. 6 5 3}$ & .086 & .232 & .123 \\
4. Alignment with goals & $\mathbf{. 6 0 9}$ & .091 & .164 & .175 \\
5. Proper project scope & $\mathbf{. 4 8 9}$ & .244 & .266 & .162 \\
6. Team member experience & -.049 & $\mathbf{. 5 2 3}$ & .352 & .158 \\
7. Member commitment & .201 & $\mathbf{. 8 3 0}$ & .119 & .070 \\
8. Team member self-control & .080 & .772 & .169 & .244 \\
9. Adequate team training & .307 &. $\mathbf{5 3 5}$ & .009 & .384 \\
10. Project leader experience & .051 & .261 & $\mathbf{. 8 0 6}$ & .090 \\
11. Project leader's control & .055 & .119 & $\mathbf{. 8 2 1}$ & .159 \\
12. Project leader's feedback & .364 & .232 & $\mathbf{. 4 3 8}$ & .382 \\
13. Detailed project plan & .322 & -.013 & $\mathbf{. 5 0 1}$ & .444 \\
14. Effective methodology & .233 & .162 & .171 &. $\mathbf{7 3 5}$ \\
15. Peer review & .032 & .238 & .340 & $\mathbf{. 6 1 6}$ \\
16. Utilizing a prototype & .004 & .124 & .101 & $\mathbf{. 8 1 1}$ \\
17. Appropriate technology & .358 & .276 & -.001 & $\mathbf{. 5 1 8}$ \\
\hline
\end{tabular}

Copyright (C) 2003, Idea Group Inc. Copying or distributing in print or electronic forms without written permission of Idea Group Inc. is prohibited. 
significantly less important than all other components, followed by Project Leader Traits and Team Member Characteristics. Organizational Integration was perceived to be the most important component. Therefore the results support Hypothesis 1.

The simple main effects analysis on the data obtained from Korean IS developers also indicated that there was a significant difference between the four components $(\mathrm{p}<.05)$. Pairwise comparisons indicated that the differences between all four components were significant. Thus, Korean IS developers viewed Project Development Management as significantly less important than all other components, while Organizational Integration was perceived as significantly more important than the other components. Therefore, the results support Hypothesis 2.

To compare the ratings by the IS developers from the two countries, a simple main effect analysis was performed on each component. The simple main effects analyses revealed that the developers in the U.S. viewed Organizational Integration and Team Member Characteristics as signifi- cantly more important than did the IS developers from Korea $(p<.05)$. The differences between the two countries were not significant on the Project Development Management and Project Leader Traits components. Thus, there was only partial support for Hypothesis 3.

\section{DISCUSSION}

The results of this survey suggest that it is possible to group the investigated strategies into four categories. The four categories were identified as (1) Organizational Integration, (2) Team Member Characteristics, (3) Project Leader Traits, and (4) Project Development Management. The results also revealed two major differences in the views of IS developers from the U.S. and Korea. Both differences may be accounted for by the differences in national culture.

The first difference between the views of the IS developers from the two countries involved the perceived importance of Organizational Integration. IS developers in the U.S. viewed this component as significantly more important than

Table 5: Mean Scores on Each Component by Nationality

\begin{tabular}{|lccc|}
\hline Component & United States & Korea & $\begin{array}{c}\text { Grand } \\
\text { Means }\end{array}$ \\
$\underline{\text { Means }}$ & & & \\
1. Organizational Integration & 6.05 & 5.85 & $\mathbf{5 . 9 4}$ \\
2. Team Members & 5.77 & 5.55 & 5.65 \\
3. Project Leader & 5.33 & 5.67 & $\mathbf{5 . 6 1}$ \\
4. Project Development Management & 5.25 & 5.33 & $\mathbf{5 . 2 9}$ \\
Grand Means & $\mathbf{5 . 6 5}$ & $\mathbf{5 . 6 0}$ & \\
\hline
\end{tabular}


did the IS developers from Korea. This may be related to the differences in how the countries view IS, which is likely the result of national cultural differences in the willingness to take risks. In the U.S., IS are frequently viewed as a means to improve business operations and provide strategic benefits. From this perspective, it would seem very logical to expect that the alignment of IS goals with organizational goals would be essential to develop an IS that is expected to provide competitive advantages. On the other hand, Korean organizations tend to view IS more in the traditional terms as an operational resource. Given this viewpoint, it might seem logical to expect that strategies associated with Organizational Integration would not be perceived to be as vital for success as it is in the case of the more sophisticated users of IT.

The second difference concerns the perceived importance of Team Member Characteristics and Project Leader Traits. IS developers in the U.S. considered the Team Members component as significantly more important than did the IS developers from Korea. Furthermore, IS developers in the U.S. viewed Team Member Characteristics as the second most important component, while Korean IS developers rated the Project Leader Traits as the second most important component. It would seem plausible that this difference could also be explained in terms of Hofstede's model on cultural differences.

The U.S. culture is one of low power distance, suggesting that members prefer to be involved and participate in decisions. The team members expect to make major contributions, and it is assumed that the project leader will delegate responsibility to the members. The U.S. culture is also characterized as high in individualism. Thus, individual team member's commitment, contribution, and cooperation are valued and expected to influence IS success. Therefore it seems logical to expect IS developers from the U.S. to perceive characteristics of the team members as a crucial component for IS success.

Conversely, the Korean culture is characterized as a high power distance culture. Thus, inequality in power is accepted in Korea and decisions are assumed to be primarily the responsibility of management. Korean employees do not expect to be involved in the strategic planning process. Thus, the success of IS may be viewed by developers from Korea as the responsibility of the project leaders who are viewed as more crucial for IS success than team members.

Despite the vast cultural differences between the U.S. and Korea, the results of this study also provided evidence of many similarities in the views of the IS developers. Developers from both countries viewed Project Development Management as the least important component. Thus, even though Korea is generally considered to be less technologically advanced (McLeod et al., 1997), there were no significant differences between the two countries in terms of their perceptions of the importance of the Project Development component.

Developers from both countries also viewed Organizational Integration as the most important component for IS success. Although some evidence suggests that IS failure may result because developers are overly concerned with technical issues (Dos Santos \& Hawk, 1988), this study demonstrates that IS developers in both countries considered organizational issues more important than methodological or tactical issues. Thus, the developers' views are consistent with the multitude of studies reporting that the most crucial factors for deter- 
mining IS success are the support of top management, user participation (Ginzberg, 1981; McDoniel et al., 1993), and clearly stated objectives and goals (Lyytinen, 1988). While this study provides evidence that IS developers appreciate the importance of organizational issues, it does not suggest that misalignment of IS will cease to contribute to IS failure. Understanding the importance of a strategy and being able to execute the strategy represent different issues. Thus, IS developers may be aware of the importance of obtaining top management support, involving users, and having clearly defined objectives. However, it may be a very arduous task in many large organizations to successfully implement these strategies (Clegg, 1997).

There are several potential explanations for the similarities observed in the perceived importance of the strategies by the developers from the two countries. First, expanding communication channels between the two countries has likely resulted in some shared values and knowledge. In addition, many scholars in Korea have been educated in the U.S. during the last few decades, creating further potential for shared beliefs. Finally, the system development process has some components that entail similar experiences, regardless of national background.

\section{CONCLUSIONS AND IMPLICATIONS FOR IS MANAGERS}

In recent years, there have been many global IS which have required managers or developers from various countries to work together in a collaborative effort in order to achieve success. In such cases, it may be useful to understand the differences in the perspectives of IS developers with different national and cultural backgrounds.
One apparent difference between the developers from the U.S. and Korea is related to how the firms in each country view the objectives of IS. Previous studies have shown that IS is viewed as more of an operational resource in Korea. Since strategies associated with Organizational Integration may not be crucial for projects that are operational in nature, the Korean developers may place less emphasis of Organizational Integration strategies. Therefore, in the development of a strategic global IS, managers may need to be aware of the possibility that developers from Korea do not perceive Organizational Integration strategies as important, as do the developers from the U.S.

The results also suggest that Team Member Characteristics and contributions are considered less important in the Korean culture. Since participation from team members is often vital for the successful development of global IS projects, mangers of global IS involving developers from Korea may find it beneficial to encourage input from Korean team members and be willing to spend more effort eliciting participation from IS developers from Korea.

The demands on managers of global IS may also be greater when the development team includes IS developers from Korea. The high uncertainty avoidance nature of the Korean culture suggests that the IS developers from Korea may expect more leadership, structure, and expertise from their managers. In Korea, there is less emphasis on the role of team members and more emphasis on the role of project leaders. Subordinates are not typically expected to provide as much input, and therefore the demands and responsibilities of the management position increases. Thus, leaders familiar with working only with developers from the U.S. may have to adjust to a more hierarchical type 
of relationship with employees from Korea and rely less of delegating responsibilities to subordinates.

In conclusion, this study provides some insights into the differences and similarities of how IS developers from two very different nations view IS development. The implications of the present study for global IS development is of course somewhat limited since the comparison was based on only two nations. In addition, the results were based on the views of developers from only eight firms in the U.S. and ten organizations in Korea. Thus, it would be beneficial if future studies could replicate these findings between the U.S. and Korea as well as examine other Asian countries. In addition, while IS developers' views are important components for assessing the effectiveness of IS development strategies, the views of users and management are also necessary for a complete assessment of the strategies. Therefore future research may expand on the current study by examining the views of users and management in order to compare and complement the views of IS developers observed in this study.

\section{REFERENCES}

Abdul-Gader, A. (1997). Information systems strategies for multinational companies in Arab Gulf countries. International Journal of Information Management, 17(1), 3-12.

Aladwani, A. M. (2000). IS project characteristics and performance: $\mathrm{A} \mathrm{Ku}$ waiti illustration. Journal of Global Information Management, 8(2), 50-57.

Baker, B. N., Murphy, D. C., \& Fisher, D. (1983). Factors affecting project success. In D. I. Cleland \& W. R. King. (Eds.), Project Management Handbook,
New York: Van Norstrand Reinhold.

Bingi, P., Leff, L. G., Shipchandler, Z. E., \& Rao, S. (2000). Critical IT implementation issues in developed and developing countries. Information Strategy: The Executive's Journal, 16(2), 25-34.

Burnson, A. (1989). The perils of going global. Infoworld, August 14, 39-40.

Chung, K. H., Lee, H. C., \& Jung, K. H. (1997). Korean Management. New York: Walter de Gruyter.

Clegg, C., Axtell, C., Damadoran, L., Farbey, B., Hull, R., Lloyd-Jones, R., Nicholls, J., Seell, R., \& Tomlinson, C. (1998). Information technology: A study of performance and the role of human and organizational factors. Ergonomics Journal, 40(9), 851-871.

Cleland, D. I., \& King, W. R. (1983). Systems Analysis and Project Management. New York: McGraw-Hill.

Dos Santos, B. L. \& Hawk, S. (1988). Differences in analyst's attitudes towards information system development: Evidence and Implications. Information \& Management, 14(1), 31-41.

Earley, P. C. (1993). East meets west meets Mideast: Further explorations of collectivistic and individualistic work groups. Academy of Management Journal, 36(2), 319-348.

Ewusi-Mensah, K. (1997). Critical issues in abandoning information systems development. Communications of the ACM, 40(9), 74-80.

Garfield, M. J. \& Watson, R. T. (1997). Differences in national information infrastructures: The reflection of national cultures. Journal of Strategic Information Systems, 6(4), 313-337.

Ginzberg, M. J. (1981). Key recurrent issues in the MIS implementation process. MIS Quarterly, 5(2), 47-59.

Grover, V., Segars, A. H., \& Durand, 
D. (1994). Organizational practice, information resource deployment and systems success: A cross-cultural survey. Journal of Strategic Information Systems, 3(2), 85-106.

Henderson, J. C. \& Lee, S., (1992). Managing I/S design teams: A control theories perspective. Management Science, 38(6), 757-777.

Hofstede, G., (1980). Culture and Organizations. International Studies of Management and Organization, 10(4), $15-41$.

Jiang, J. J., Klein, G., \& Balloun, J. (1996). Ranking of system implementation success factors. Project Management Journal, 27(4), 49-53.

Jiang, J. J., Klein, G., \& Balloun, J. (1998). Perceptions of system development failures. Information and Software Technology, 39(14-15), 933-937.

Jones, M. C. \& Harrison, A. W. (1996). IS project team performance: An empirical assessment. Information \& Management, 31(2), 57-65.

Katz, J. P. \& Townsend, J. B. (2000). The role of information technology in the "Fit" between culture, business strategy and organizational structure of global firms. Journal of Global Information Management, 8(2), 24-35.

Kirsch, L. J. (1997). Portfolios of control modes and IS project management. Information Systems Research, 8(3), 215 239.

Kirsch, L. J. \& Cummings, L. L. (1996). Contextual influences on self-control of IS professionals engaged in systems development. Accounting, Management and Information Technologies, 6(3), 191219.

Kumar, K. \& Bjorn-Andersen, N. (1990). A cross-cultural comparison of IS designer values. Communications of the
ACM, 33(5), 528-538.

Liebowitz, J. (1999). Information systems: Success or failure? Journal of Computer Information Systems, 40(1), 17-20.

Lyytinen, K. (1988). Expectation failure concept and systems analysts' view of information system failures: Results of an exploratory study. Information \& Management, 14(1), 45-56.

McDoniel, P. L., Palko, J., \& Cronan, T. P. (1993). Information systems development issues affecting success. Journal of Computer Information Systems, 34(1), 50-62.

McIntosh, J. C. (1999). Strategic uses of global information technology among manufacturing firms. Journal of Global Information Technology Management, 3(2), 24-41.

McLeod, R., Kim, C. N., Saunders, C., Jones, J. W., Scheel, C., \& Estrada, M. C. (1997). Information management as perceived by CIOs in three Pacific rim countries. Journal of Global Information Management, 5(3), 5-16.

Nath, R. (1989). Aligning MIS with the business goals. Information \& Management, 16(2), 71-79.

Park, H. K., Chun, K. I., Lim, J. S., \& Min, J. K. (1998). A comparative study of the use of executive information systems between Korea and the United States. Journal of International Information Management, 7(2), 1-14.

Pinto, J. \& Prescott, J. E. (1990). Planning and tactical factors in the project implementation process. Journal of Management Studies, 27(3), 305-327.

Pinto, J. \& Slevin, D. P. (1987). Critical factors in successful project implementation.IEEE Transactions on Engineering Management, 34(1), 22-27. Ratbe, D., King, W. R., \& Kim, Y. (2000). The fit between project characteristics and application development meth- 
odologies: A contingency approach. Journal of Computer Information Systems, 40(2), 26-33.

Roberts, T. L. Leigh, W., \& Purvis, R. L. (2000). Perceptions on stakeholder involvement in the implementation of system development methodologies. Journal of Computer Information Systems, 40(3), 78-83.

Ronen, S. \& Shankar, O. (1985). Clustering countries on attitudinal dimensions: A review and synthesis. Academy of Management Review, 10(3), 435-454.

Sekaran, U. \& Snodgrass, C. R. (1986). A model for examining organizational effectiveness cross-culturally. $A d$ vances in International Comparative Management, 2, 211-232.

Shore, B. (1998). IT strategy: The challenge of over-regulation, culture, and large scale collaborations. Journal of Global Information Technology Management, 1(1), 1-4.

Shore, B. \& Venkatachalam, V. (1994). Prototyping: A metaphor for crosscultural transfer and implementation of IS applications. Information \& Management, 27(3), 175-184.

Sondergaard, M. (1994). Hofstede's consequences; A study of reviews, citations and replications. Organizational Studies, 15(3), 447-456.

Vitale, M. R. (1986). The growing risks of information success. MIS Quarterly, 10(4), 327-334.

Watson, R. T., \& Brancheau, J. C. (1991). Key issues in IS management: An international perspective. Information \& Management, 20(3), 214-223.

Chung S. Kim is a professor in the Department of Computer Information Systems at Southwest Missouri State University, USA. She received her Ph.D. in MIS from Texas Tech University. Her current research interests include system development methodologies, business reengineering, and cultural issues in system development practices. Her research results have been published in journals, such as Information \& Management, Journal of Computer Information Systems, the Journal of Global Information Management, and Journal of Information Technology Management.

Dane K. Peterson is a professor of Quantitative Business Analysis at Southwest Missouri State University, USA. He has a Ph.D. in quantitative and applied psychology from Southern Illinois University. His research interests include issues related to global information management and business and computer ethics. He has published in numerous journals, including the Journal of Applied Psychology, Journal of Global Information Management, Organizational Behavior and Human Decision Processes, International Journal of Information Management, and the Journal of Business Ethics. 